\title{
Fluctuations of high-sensitivity C-reactive protein in acute coronary syndrome
}

\author{
Wickramatilake $\mathbf{C M}^{\mathbf{1}}$, Mohideen $\mathbf{M R}^{2}$, Pathirana $\mathbf{C}^{\mathbf{1}}$ \\ ${ }^{1}$ Department of Biochemistry, ${ }^{2}$ Department of Medicine, Faculty of Medicine, University of Ruhuna, Galle, \\ Sri Lanka
}

Correspondence: Dr. C.M. Wickramatilake

Department of Biochemistry, Faculty of Medicine, University of Ruhuna, Galle, Sri Lanka

E-mail: chandimadhu@live.com

\begin{abstract}
Background: Atherosclerosis is associated with low-grade vascular inflammation that can be measured with high sensitivity-C reactive protein (hs-CRP). Acute coronary syndrome (ACS) events are thought to occur due to plaque rupture which is induced by the inflammatory process. Therefore with the onset of ACS there is a rise of hs-CRP from the baseline levels. This study was carried out to observe the fluctuations in serum hs-CRP concentrations after ACS and to determine the optimal time for blood sampling for hs-CRP that represents the baseline value.
\end{abstract}

Methods: Serial estimates of serum hs-CRP were done in patients admitted with ACS by turbidimetry. Samples were taken, on admission, day three, five, 24 and 84 from the onset of symptoms.

Results: Eight male patients (mean age 53, SD 5 yrs) with ACS (five with ST- elevation myocardial infarction and three with unstable angina) were included. Serum mean (SD) hs-CRP level on admission was 3.06 (1.3) $\mathrm{mg} / \mathrm{L}$. Then levels rose to $6.17(2.6) \mathrm{mg} / \mathrm{L}$ on day three; was significantly different from on admission value $(p=$ $0.013)$. Then it declined to $4.37(1.8) \mathrm{mg} / \mathrm{L}$ on day five and on $24^{\text {th }}$ day to $3.21(1.2) \mathrm{mg} / \mathrm{L}$. The value on $84^{\text {th }}$ day was $3.12(1.4) \mathrm{mg} / \mathrm{L}$. No significant difference was observed between the mean hs-CRP level on admission and on day five $(P=0.20)$, on day $24(p=0.81)$ and on day $84(p=0.93)$, respectively.

Conclusion: Serum hs-CRP fluctuates after ACS, peaked on day three, returns to the basal level by day five following the acute event. Therefore basal level is more reliably reflected by the on admission sample.

Key words: High sensitivity C-reactive protein; Acute Coronary Syndrome

\section{Introduction}

Atherothrombosis of the coronary and cerebral vessels is understood as a disorder of inflammation and a disorder of lipid accumulation (1). Atherogenesis is a process of cellular adhesion, monocyte and macrophage attachment, and transmigration of immune cells across the endothelium. In the later stages, there is transition of mature stable plaque to unstable plaque, rupturing at the time of acute thrombosis (2).

C-reactive protein, a sensitive marker of the acutephase response, has attracted increasing attention in recent years because many epidemiologic studies have shown consistent positive associations between high-sensitivity CRP (hs-CRP) concentrations in the peripheral circulation and the risk of future cardiovascular events, independently of established risk factors. There is clinical evidence demonstrating that many biomarkers of inflammation are elevated years in advance of first ever myocardial infarction (MI), and that these biomarkers are highly predictive of recurrent MI, recurrent stroke and cardiovascular death $(3,4)$. 
In clinical practice, the inflammatory biomarker in widest use is hs-CRP. When interpreted within the context of usual risk, levels of hs-CRP $<1,1$ to 3 , and $>3 \mathrm{mg} / \mathrm{L}$ denote lower, average, and higher relative risk for vascular events (5).

The hs-CRP is involved in the inflammatory process linked to ischemic myocardial damage and necrosis and there are reports that $\mathrm{C}$-reactive protein levels increase during acute myocardial infarction (AMI) and unstable angina (UA) $(6,7)$.

A patient admitted with an ACS may have a variable course with respect to the serum hs-CRP concerned. Therefore it is important to determine the optimum time to obtain the sample of blood that reflects the basal level of hs-CRP in these patients. There are few reports on serial measurements of hs-CRP during the period after acute myocardial infarction and the findings are inconsistent.

Therefore this study was carried out to study the fluctuations in serum hs-CRP concentrations after ACS and to determine the optimal time for blood sampling for hs-CRP that represents the baseline value.

\section{Methods}

This research was conducted as a part of a larger study investigating the association of total testosterone and hs-CRP with coronary artery disease and its severity in men. The ethical clearance was obtained from the Ethical Review Committee of Faculty of Medicine, University of Ruhuna, Galle. The protocol for this study was approved by the authorities of Teaching Hospital, Karapitiya, Galle. Informed written consent was obtained from all participants of the study. Study subjects included were male patients admitted to the Emergency Treatment Unit and the Coronary Care Unit with acute coronary syndrome.

Diagnosis was made on the basis of typical history and electrocardiographic changes and all recruited patients fulfilled the American College of Cardiology/American Heart Association criteria for acute coronary syndrome (8).

Consecutive male patients in the age range of 30-73 years were included within a period of three months. During the baseline interview on discharge from the hospital, information was gathered using an interviewer - administered questionnaire. Height and weight were also recorded. The hospital stay of the patient varied from three to five days.

The level of serum hs-CRP was estimated in eight male patients with ACS, which included five patients with ST-segment-elevation-myocardial infarction, and three patients with unstable angina. Three samples of blood were collected during the hospital stay; first sample on admission, second sample on day three and a third sample on day five from the onset of symptoms. Following discharge from the hospital, two further samples were obtained on day 24 and on day 84 (12 weeks) after the acute ischaemic episode. The on admission sample was obtained around mean of 8.8 hours from the onset of symptoms. Blood samples $(5 \mathrm{ml})$ were drawn by venipuncture and serum was separated by centrifugation and stored at $-70^{\circ} \mathrm{C}$ until assayed.

Serum hs-CRP was measured by commercially available test kit based on turbidimetry (DIAgAM, Rue du Parc Industrial, 7822, GHISLENGHIEN Belgium). The analytical range of the test kit was $0.005-16.00 \mathrm{mg} / \mathrm{L}$, and intra-assay and inter-assay coefficient of variations were less than $1 \%$. Assays were performed blind with respect to the information of the study subject. Total serum cholesterol and plasma glucose were measured by enzyme-based colourimetry methods using commercially available test kits (ProDia International, UAE).

Data were analyzed by Minitab software (version 15 for Windows). Raw data were inspected for normality and were presented as mean \pm SD. Serum hs-CRP levels at different time intervals were analyzed by two samples $t$-test.

\section{Results}

One patient died of recurrent myocardial infarction before the final sample was obtained and three patients dropped out from 12 patients who were initially recruited. The data of eight patients were presented. All patients with ST-elevation myocardial infarction (STEMI) received thrombolytic therapy with streptokinase. There were no patients who developed heart failure, serious arrhythmias or reinfarctions. The basic characteristics of patients are shown in Table 1. 
Table1: Characteristics of eight subjects admitted with acute coronary syndrome

\begin{tabular}{lc}
\hline \multicolumn{1}{c}{ Variable } & Mean (SD) \\
\hline Age (yrs) & $53(5)$ \\
Body mass index $\left(\mathrm{kgm}^{-2}\right)$ & $21(3)$ \\
Total cholesterol $(\mathrm{mmol} / \mathrm{L})$ & $4.9(0.6)$ \\
Fasting blood sugar $(\mathrm{mmol} / \mathrm{L})$ & $5.8(1.9)$ \\
Systolic blood pressure on admission $(\mathrm{mmHg})$ & $147(20)$ \\
Diastolic blood pressure on admission $(\mathrm{mmHg})$ & $90.7(17)$ \\
Ejection Fraction on 2DEcho & $52.5 \%(0.1)$ \\
Pulse rate on admission (beats/min) & $73(19)$ \\
\hline Presence of risk factors on admission & $(\mathrm{Number})$ \\
\hline Current smokers & 5 \\
Diabetes mellitus & 2 \\
Hypertension & 3 \\
Hypercholesterolaemia/dyslipidaemia & 2 \\
\hline
\end{tabular}

Data as mean $\pm \mathrm{SD}, 2 \mathrm{DEcho:} 2$ Dimensional echocardiography

Mean (SD) serum hs-CRP concentration on admission was $3.06(1.3) \mathrm{mg} / \mathrm{L}$. Then concentration rose to 6.17 (2.6) $\mathrm{mg} / \mathrm{L}$ on day three and peaked. The concentration declined thereafter to $4.37(1.8) \mathrm{mg} / \mathrm{L}$ on day five appeared returning to the values seen on admission. The mean hs-CRP concentration on day 24 and 84 were 3.21 (1.2) $\mathrm{mg} / \mathrm{L}, 3.12(1.4) \mathrm{mg} / \mathrm{L}$ respectivelv. Fluctuations of mean serum hs-CRP concentration at different time intervals wer

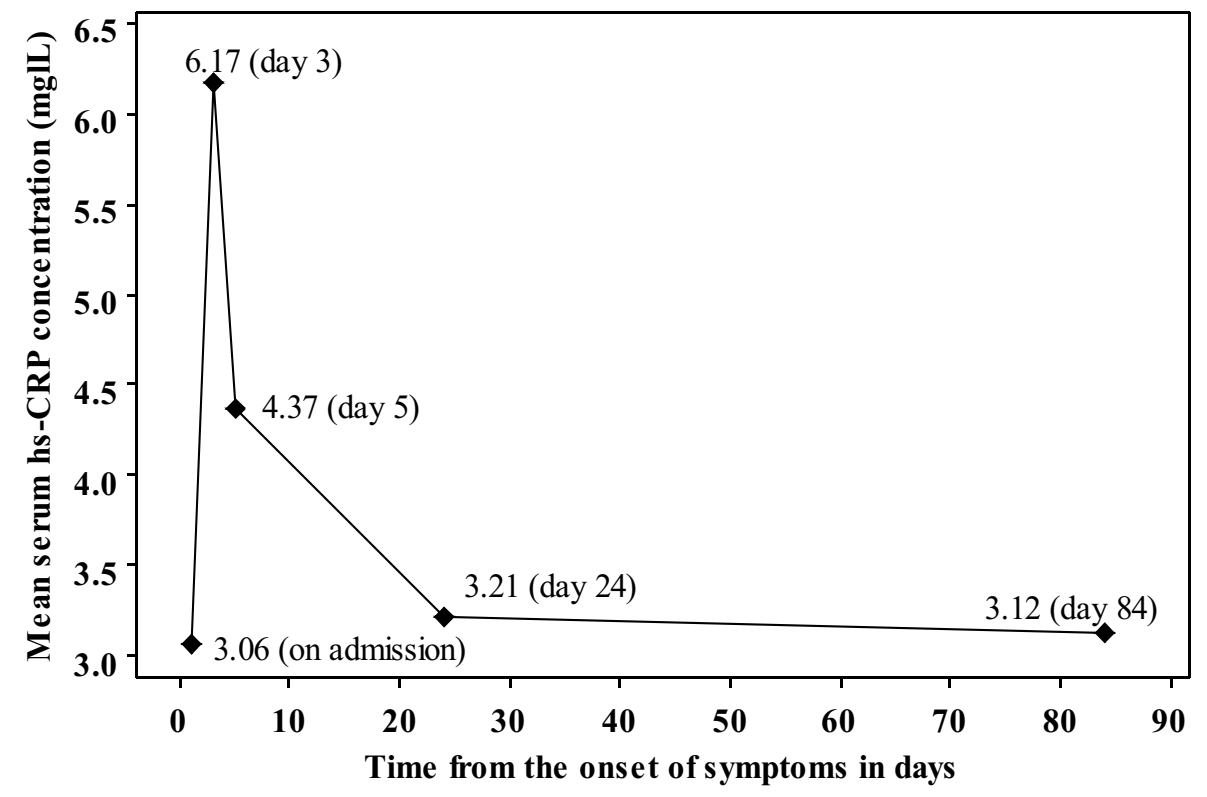

Figure 1: Fluctuations of serum hs-CRP in acute coronary syndrome 
Figure 1. The hs-CRP concentration on admission $(3.06 \mathrm{mg} / \mathrm{L})$, on day five, $(4.37 \mathrm{mg} / \mathrm{L})$, on day 24 $(3.21 \mathrm{mg} / \mathrm{L})$ and on day $84(3.12 \mathrm{mg} / \mathrm{L})$ were not significantly different. Peak concentration (6.17 $\mathrm{mg} / \mathrm{L}$ ) was achieved on day three.

The highest concentration was achieved on day three $(6.17 \mathrm{mg} / \mathrm{L})$ and was significantly different from the concentrations on admission $(6.17 \mathrm{mg} / \mathrm{L}$ vs. 3.06 $\mathrm{mg} / \mathrm{L}, p=0.013)$, on day $24(6.17 \mathrm{mg} / \mathrm{L}$ vs. $3.21 \mathrm{mg} / \mathrm{L}$, $p=0.017)$, on day $84(6.17 \mathrm{mg} / \mathrm{L}$ vs. $3.12 \mathrm{mg} / \mathrm{L}$, $p=0.015)$, but it is not significantly different from day five concentration $(6.17 \mathrm{mg} / \mathrm{L}$ vs. to $4.37 \mathrm{mg} / \mathrm{L}$ $p=0.17$ ).

It was noted that no significant difference was observed between the mean hs-CRP concentration on admission and on day five $(3.06 \mathrm{mg} / \mathrm{L}$ vs. $4.37 \mathrm{mg} / \mathrm{L}, p=0.20)$, day $24(3.06 \mathrm{mg} / \mathrm{L}$ vs. 3.21 $\mathrm{mg} / \mathrm{L}, p=0.81)$, day $84(3.06 \mathrm{mg} / \mathrm{L}$ vs. $3.12 \mathrm{mg} / \mathrm{L}$, $p=0.93)$, respectively.

\section{Discussion}

In the present study serial estimation of hs-CRP in a group of patients with ACS from admission to 12 weeks (84 days) showed significant fluctuations. The hs-CRP level peaked on day three and declined to the on admission level (basal level) by day five and remained relatively unchanged thereafter up to 12 weeks ( 84 days).

The acute-phase response of C-reactive protein is considered to be non-specific and reflects cytokinemediated hepatic production triggered by inflammation, infection, and tissue injury (1). Plasma levels of CRP usually start to rise about 6 hours after an acute stimulus, reaching a peak by 48 hours. The level then decreases at a rate close to the measured plasma half-life of CRP of about 19 hours (9) with the abrupt cessation of the stimulus. Evidence suggests that inflammation within the atherosclerotic plaque contributes to its destabilization and subsequent disruption (2).

The results of our study are in keeping with other studies which report that C-reactive protein levels increase in acute coronary syndrome $(6,7,10)$. Majority of studies showed that hs-CRP usually peaks from 48 hours to 72 hours from the onset of symptoms of ACS $(6,11,12)$. These study findings are in line with our study, which revealed 72 hours (day three) as the time when hs-CRP peaks following ACS.
There are other factors that may also influence the rise and variation of serum hs-CRP. Thrombolysis therapy and early reopening of the infarct-related artery in AMI patients can lead to low CRP levels or a smaller rise than expected in some patients (13). It is reported that elevation of hs-CRP can be lowered with the treatment of statin (14) and aspirin (15). C-reactive protein may also be used as a surrogate marker of infarct size (13).

Therefore there is indisputable evidence of a rise of CRP in ACS. The fluctuations depend on the type and size of myocardial infarction and are also influenced partly by treatment, which may affect the time of peaking.

In conclusion, serum hs-CRP fluctuates after ACS, peaked at day three, returns to the basal level by day five following ACS. Therefore basal level is more reliably reflected by the on admission sample.

\section{Acknowledgement}

We wish to acknowledge the University Grants Commission, Sri Lanka for the financial assistance provided for the project (Grant No: UGC/ICD/CRF/ 2009/2/47).

\section{References}

1. Ballantyne $\mathrm{CM}$, Hoogeveen $\mathrm{RC}$, Bang $\mathrm{H}$, et al. Lipoprotein-associated phospholipase A2, high-sensitivity C-reactive protein, and risk for incident coronary heart disease in middle-aged men and women in the Atherosclerosis Risk in Communities (ARIC) study. Circulation 2004; 109: 837-42.

2. van der Wal AC, Piek JJ, de Boer OJ, et al. Recent activation of the plaque immune response in coronary lesions underlying acute coronary syndromes. Heart 1998; 80(1): 14-8.

3. Ridker PM, Hennekens CH, Buring JE, Rifai N. C-reactive protein and other markers of inflammation in the prediction of cardiovascular disease in women. New England Journal of Medicine 2000; 342: 836-43.

4. Ridker PM, Rifai N, Rose L, Buring JE, Cook NR. Comparison of C-reactive protein and low density lipoprotein cholesterol levels in the prediction of first cardiovascular events. New England Journal of Medicine 2002; 347: 1557-65. 
5. Pearson TA, Mensah GA, Alexander RW, et al. Markers of inflammation and cardiovascular disease: Application to clinical and public health practice: A statement for healthcare professionals from the Centers for Disease Control and Prevention and the American Heart Association. Circulation 2003; 107: 499-511.

6. Cusack MR, Marber MS, Lambiase PD, Bucknall CA, Redwood SR, Systemic inflammation in unstable angina is the result of myocardial necrosis. Journal of American College of Cardiology 2002; 39(12): 1917-23.

7. Zebrack JS, Anderson JL, Maycock CA, et al. Usefulness of high-sensitivity $\mathrm{C}$-reactive protein in predicting long-term risk of death or acute myocardial infarction in patients with unstable or stable angina pectoris or acute myocardial infarction. American Journal Cardiology 2002; 89(2): 145 9.

8. The Task Force for the Diagnosis and Treatment of Non-STSegment Elevation Acute Coronary Syndromes of the European Society of Cardiology. Guidelines for the diagnosis and treatment of non-ST-segment elevation acute coronary syndromes. European Heart Journal 2007; 28: 1598-660.

9. Vigushin DM, Pepys MB, Hawkins PN. Metabolic and scintigraphic studies of radioiodinated human C-reactive protein in health and disease. The Journal of Clinical Investigation 1993;91(4); 1351-7.
10. Brunetti ND, Troccoli R, Correale M, Pellegrino PL, Di Biase M. C-reactive protein in patients with acute coronary syndrome: Correlation with diagnosis, myocardial damage, ejection fraction and angiographic findings. International Journal of Cardiology 2006; 109(2): 248-56.

11. Berton G, Cordiano R, Palmieri R, et al. C-reactive protein in acute myocardial infarction: association with heart failure. American Heart Journal 2003; 145: 1094-101.

12. Gabriela AS, Martinssona A, Wretlindb B, Ahnvea S. IL-6 levels in acute and post myocardial infarction: their relation to CRP levels, infarction size, left ventricular systolic function, and heart failure. European Journal of Internal Medicine 2004; 15: 523-8.

13. Pietilä K, Harmoinen A, Hermens W, et al. Serum Creactive protein and infarct size in myocardial infarct patients with a closed versus an open infarct-related coronary artery after thrombolytic therapy. European Heart Journal 1993; 14:915-9.

14. Berthold HK, Berneis K, Mantzoros CS, Krone W, GouniBerthold I. Effects of simvastatin and ezetimibe on interleukin-6 and high-sensitivity C-reactive protein. Scandinavian Cardiovascular Journal 2013; 47(1): 20-7.

15. Kennon S, Price CP, Mills PG, et al. The effect of aspirin on $\mathrm{C}$-reactive protein as a marker of risk in unstable angina. Journal of the American College of Cardiology 2001; 37(5): 1266-70. 